\title{
Roundtable
}

\section{On the dangers of interpopulational transfers of monarch butterflies}

I n North America there are two migratory populations of the monarch butterfly, Danaus plexippus L. (Nymphalidae). There is an enormous eastern population, which migrates between a summer breeding area east of the Rocky Mountains and overwintering areas in central Mexico, and there is a smaller western population, which breeds west of the Rocky Mountains and migrates to overwinter in numerous sites along the California coast (Figure 1). The degree of natural interchange between the eastern and western populations is unknown; despite nearly 60 years of debate, no quantitative data address this question (Brower in press). We recently became aware of experiments in which adult monarch butterflies captured or reared from eastern populations are being released west of the Rockies, and vice versa. Transfers have been made from Wisconsin to California (number unknown, Anonymous 1992), from California to North Carolina ( $\mathrm{N}=1500$, Cherubini 1994), from Nebraska to Oregon ( $N=300$, Anonymous 1994), and from Pennsylvania to Oregon ( $\mathrm{N}=56$, Steffy 1994). In articles in The Monarch Newsletter (1994-1995, volume 5, issues 2-4), butterfly specialists are debating the wisdom of this practice. We believe, however, that the

by Lincoln P. Brower, Linda S. Fink, Andrew Van Zandt Brower, Kingston Leong, Karen Oberhauser, Sonia Altizer, Orley Taylor, Danel Vickerman, William H. Calvert, Tonya Van Hook, Alfonso AlonsoMejia, Stephen B. Malcolm, Denis F. Owen, and Myron P. Zalucki situation should be brought to the attention of a broader community of biologists.

We offer three arguments against transferring monarch butterflies between distinct populations: Transferred butterflies can carry infectious and potentially lethal diseases into susceptible populations; transfers may confuse our understanding of numerous aspects of the monarch's basic biology; and the hypotheses purportedly being tested with these transfers are unanswerable by this technique.

Disease risk is a potentially disastrous consequence of artificially mixing populations. There is increasing recognition among ecologists that diseases have significant impacts on wild populations and that diseases may cause or exacerbate conservation problems (e.g., Thorne and Williams 1988, Wilson et al. 1994). While most studies have focused on birds and mammals, several insect epidemics are also well documented.

The parasitic mite, Varroa jacobsoni, was first reported in colonies of the European honey bee, Apis mellifera, in the mid-1960s. By 1970 many colonies were being killed by the mites in Japan and eastern Europe, and mite-caused mortality rapidly spread across western Europe, North America, and South America (Beetsma 1992). One factor important in the mite's range expansion has been the export of infected colonies and queens. Some colonies are more resistant to the mites, due to naturally occurring variation in bee development time, nest-cleaning behavior, and grooming behavior (Boecking and Ritter 1994).

In California, a rickettsial bacteria that resembles Wolbachia is spreading through populations of the fruit fly Drosophila simulans
(Drosophilidae) at the rate of more than $100 \mathrm{~km}$ per year. It takes less than three years for a population to become almost completely infected. Analyses suggest that the rapid spread may be partly attributed to occasional long-distance dispersal of individuals (Turelli and Hoffmann 1991).

These examples could foreshadow the monarch's fate if east-to-west and west-to-east transfers continue. One candidate pathogen is the neogregarine protozoan Ophryocystis elektroscirrha, which infects both monarch and queen butterflies (Danaus gilippus berenice Cramer; McLaughlin and Myers 1970). The effects of repeated infection of successive generations in the laboratory are cumulative, and after two or three generations the butterflies are so diseased that they fail to develop properly, cannot emerge successfully from their chrysalids, or die shortly after emerging.

Ophryocystis spores are spread in three ways: horizontally by venereal transfer from male to female and vice versa during mating ${ }^{1}$; horizontally by other physical contact between healthy and infected adults (confirmed experimentally in the laboratory with caged butterflies) ${ }^{2}$; and vertically by transfer from a female to offspring (spores rub off a female's cuticle onto her eggs or onto the host plant). Infection occurs subsequently when a caterpillar swallows the spores (McLaughlin and Myers 1970). Because dense clusters of adults form during the monarch's fall migration and at the overwintering sites, the transfer of disease from adult to adult is particularly ominous. Butterfly density

${ }^{1}$ S.Altizer, 1994, unpublished data.

${ }^{2}$ S. Altizer, 1994, unpublished data; D. Vickerman and O. Taylor, 1994, unpublished data. 
Figure 1. Migration routes of the monarch butterfly in North America. a. The western population breeds west of the Rocky Mountains during the spring and summer and migrates to numerous overwintering sites, mainly along the California coast, from north of San Francisco to south of Los Angeles. The vastly larger eastern population breeds east of the Rocky Mountains and migrates to winter at a few spectacular overwintering sites in the Transverse Neovolcanic Belt, south of the Tropic of Cancer in central Mexico. The magnitude of a fall migration across the Gulf of Mexico is uncertain. b. Overwintering individuals of the western population migrate in early spring into the Coast Ranges, the Central Valley, and the Sierra Nevada where they lay their eggs on the resurgent milkweed flora and produce the first spring generation. Monarchs that overwintered in Mexico remigrate at the end of March and early April to the Gulf Coast states and produce a new spring generation on the southern milkweeds. This new generation then flies northwards to southern Canada and breeds in an area of approximately $\mathbf{2 . 2}$ million $\mathrm{km}^{2}$. After three or four spring and summer generations, the monarchs enter reproductive diapause and migrate to their respective overwintering sites. Spring migration across the Gulf of Mexico is also open to question. (From Brower in press, used with permission of the Lepidopterists' Society.)

in Mexico has been conservatively estimated to be ten million monarchs per hectare.

Leong et al. (1992) determined that $O$. elektroscirrha is present to a high degree in coastal California overwintering populations. In the winter of 1990-1991, Leong and colleagues found $53 \%$ and $68 \%$ of individuals sampled at two sites to be infected. Similarly, Elizabeth Bell at the University of California at Santa $\mathrm{Cruz}^{3}$ has measured infection rates of $30-60 \%$ at Santa Cruz sites. Altizer and colleagues ${ }^{4}$ have found that populations from Minnesota, Kansas, and Texas, as well as monarchs from several overwintering sites in Mexico, are infected but to lesser degrees than the western populations. Only three monarchs from

${ }^{3}$ E. Bell, 1994, personal communication. University of California, Santa Cruz, CA.

${ }^{4} \mathrm{~S}$. Altizer, A. Alonso-Mejia, A. Knight, L. Brower, and $\mathrm{K}$. Oberhauser, manuscript in preparation. a

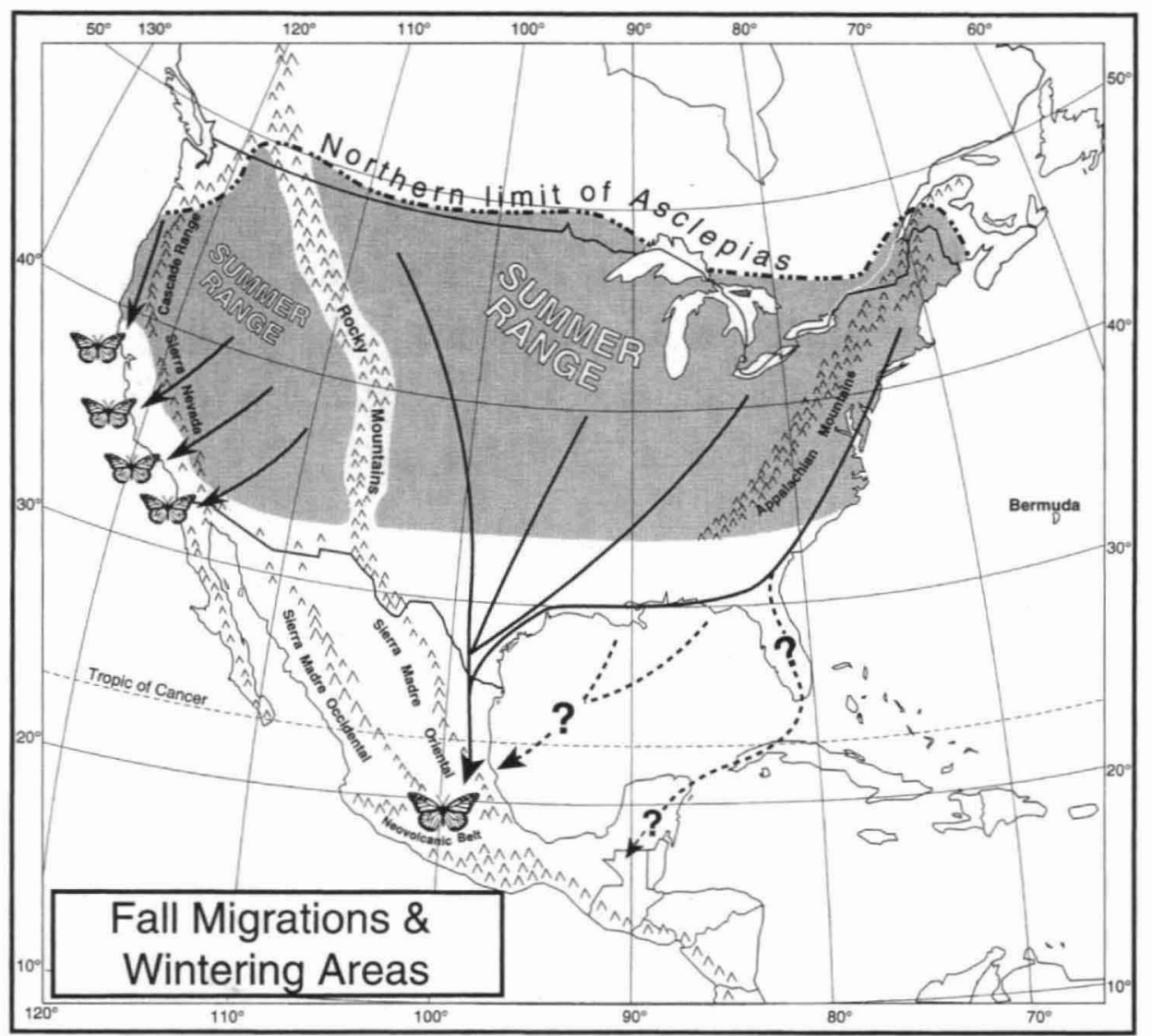

b

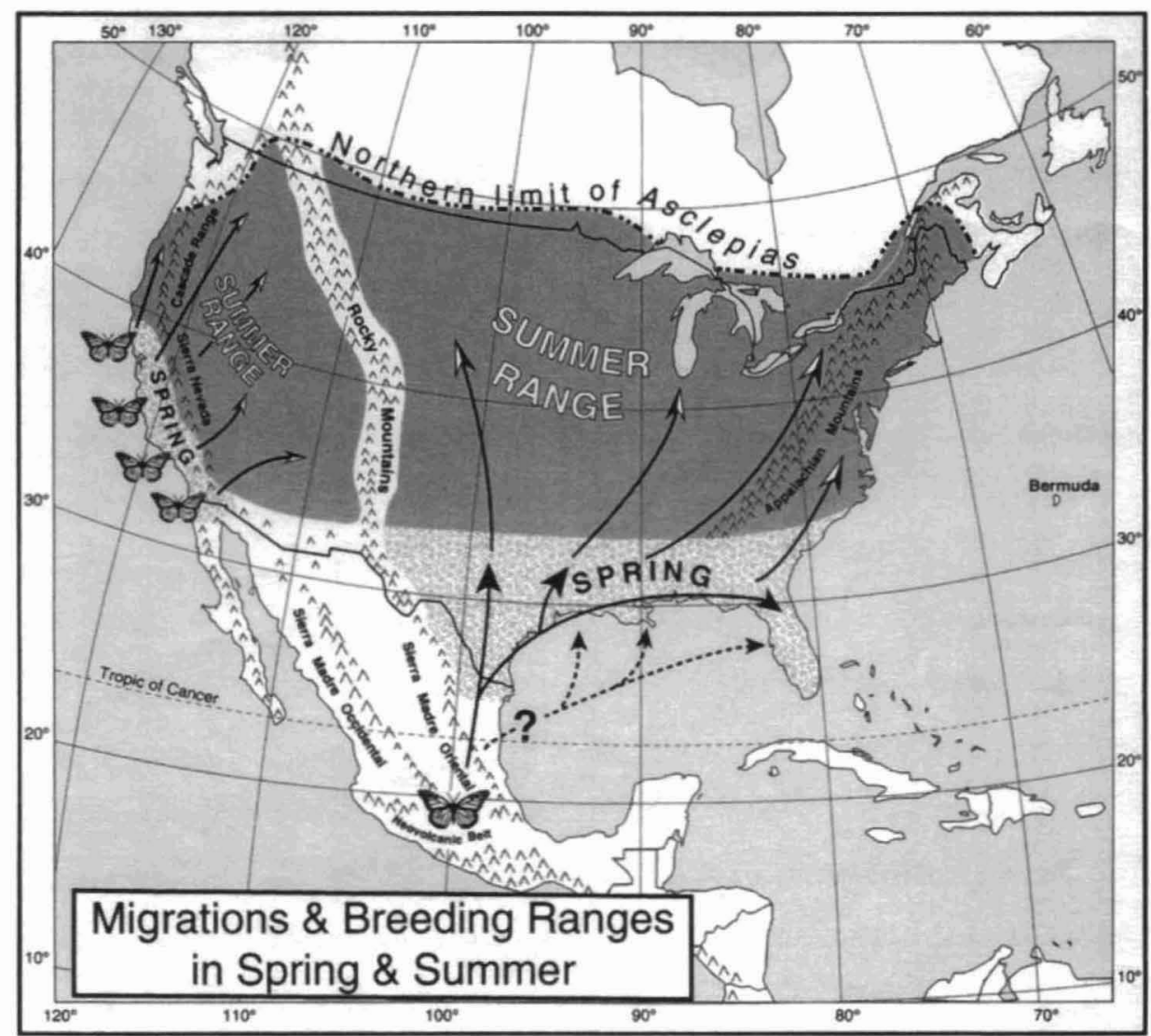


Hawaii have been examined to date, but all were heavily infected. ${ }^{5}$ Currently, we do not know the degree to which the disease contributes to mortality of wild butterflies. However, lepidopterists who have encountered $O$. elektroscirrha while rearing monarchs attest to its highly infectious, debilitating, and ultimately lethal nature.

Although the pathogen is present on both sides of the Rocky Mountains, an insidious possibility is that several neogregarine species or distinct strains may occur in different populations of monarch butterflies. If so, the impact of strains introduced through butterfly transfers could be more severe than the impact within the original host populations. We should take warning from the harsh effects of new strains of previously encountered pathogens, such as influenza, in human populations.

The numbers of monarch butterflies at California overwintering sites in the winter of 1994-1995 were the lowest on record. At the Pismo State Beach colony, for example, Sakai (1995) estimated the population at 15,000 , one-tenth its usual number. At this time, it is not possible to rule out infection by Ophryocystis as one cause of the butterflies' scarcity.

Transfers could destroy the possibility of understanding numerous aspects of the basic biology of the monarch. Although the monarch butterfly is one of the best studied nonpest insects (Malcolm and Zalucki 1993), we know little about the biological differences between the eastern and western populations. Deliberate transfers are likely to result in reciprocal gene flow and decrease any existing differentiation between the populations. Analysis of monarch mitochondrial DNA revealed almost no polymorphism either within or between samples from Mexico, California, and the West Indies (Brower and Boyce 1991). Using electrophoresis, however, Eanes and Koehn (1978) found substantial allozyme variation in eastern samples. Comparable electrophoretic data for western monarchs are not available.

${ }^{5}$ O. Taylor, 1994, unpublished data.
Possible differences between the eastern and western populations include, but are not limited to, the following:

- The eastern population migrates to a handful of sites in a tiny region of Mexico to overwinter, while the western population overwinters in more than 200 sites stretching along much of the California coast. The problems of orientation and navigation faced by migrants in the two populations are different. For example, in both populations many migrants encounter large bodies of water (the Great Lakes, Atlantic Ocean, and Gulf of Mexico in the east, and the Pacific Ocean in the west). Because the orientations of these coastlines relative to the overwintering destinations differ, eastern and western migrants may demonstrate different directional responses to large bodies of water. - The macro and microclimates of the high-altitude overwintering sites in Mexico are vastly different from those in the coastal overwintering sites in California. The two populations probably have different responses to cold temperatures, including biochemical, physiological, and/or behavioral adaptations. We know, for example, that monarchs migrating to Mexico build up much larger lipid reserves than those migrating to overwintering sites in California (Brower 1985, Tuskes and Brower 1978).

- The timing of the spring migrations, and sexual behavior at the overwintering sites, differ in the east and west. In California, almost all overwintering female butterflies mate at the sites between December and March, while in Mexico fewer of the butterflies mate before departing (Brower 1985, Herman et al. 1989).

- The milkweed flora differs east and west of the Rockies. Milkweeds vary in, for example, their cardenolide chemistry, phenologies, and life forms, and we do not know the extent of coevolution between populations of the monarch and these two floras.

The multiplicity of known and likely differences imply that suites of adaptations under genetic con- trol could differ substantially in the two populations. It is conceivable that transfers could result in considerable genetic disequilibrium and force massive selective reorganization and genetic deaths in both populations.

In addition, human-caused gene flow could make it impossible to estimate the degree of natural interchange of monarch butterflies across the Rocky Mountains (Brower in press, Malcolm and Zalucki 1993). Transfers could also muddle our ability to understand the monarch's nineteenth-century transpacific dispersal, including the pattern of island-hopping and the colonizations of Australia and New Zealand (Vane-Wright 1993).

Deliberate transfers of individuals between donor and recipient populations with subtle genetic differences have resulted in conservation and management problems in several taxa. For example, on small oceanic islands off of New Zealand's North Island, small relict populations of the tuatara (Sphenodon), large iguana-like animals, are the only survivors of an order of reptiles that flourished during the Triassic, 200 million years ago. Recent allozyme analyses have indicated that several islands support genetically distinct populations and even different species. Attempts to conserve the diminishing populations by legislation ignored known taxonomic differences and transferred animals among the islands. Ignoring these differences has unfortunately resulted in the loss of several welldifferentiated populations and possibly even one species (Daugherty et al. 1990).

The hypotheses purportedly being tested by the transfer experiments have never been clearly articulated, are not being posed in rigorously testable form, and, even if reformulated, are unlikely to be answerable with available methodology. Urquhart and Urquhart (1972, 1974, review in Urquhart 1987) organized reciprocal transfers of thousands of monarchs between eastern and western populations in order to answer the following question: Would monarch butterflies continue to travel southward or southwestward dur- 
ing the fall migration if they were transferred from one part of North America to another? Recaptures of released, tagged individuals indicated that at least some did still travel south, but there was no gain of any further knowledge of the monarch's biology. The number of monarchs transferred by the Urquharts and their collaborators has never been published.

Two purposes have been stated for the current round of butterfly transfers: "to determine how California monarchs behave east of the continental divide" (Cherubini 1994), and to determine if the direction of migration is "innate...or determined directly by the butterflies from stimuli perceived in the external environment of the release location itself" (Cherubini 1995). The first question has already been answered by the Urquharts' transfers. Monarchs captured at Muir Beach, California, and released in North Dakota flew south and were recaptured in Nebraska and Kansas (Urquhart and Urquhart 1974). The second question, unraveling the influences of genetic and environmental factors on monarch orientation and navigation, is more complex. It is not clear how our understanding is to be advanced by haphazard transfers, which lack a carefully designed protocol and are unrelated to any laboratory experiments.

The potential to gain new insights about migration from monarch tagging, beyond those already obtained by the Urquharts and their associates, is limited because of the extremely low rate at which tagged butterflies are recaptured far from their release sites (Table 1 ). The proportion of butterflies recaptured more than $100 \mathrm{~km}$ from their point of release generally does not exceed 2 in 1000 . Even with a recent claim of $10 \%$ return rates (Cherubini 1995), the numbers are still low. Thus, to obtain a statistically valid test of alternative hypotheses, transfers of thousands of butterflies would be required, exacerbating the biological and disease problems we have addressed.

An unknown number of transfers are also being conducted by schools. Some monarch rearers, including commercial suppliers, mail various life-history stages to teachers for their students to rear, tag, and release. While we do not know the extent of these mailings, we are concerned that unless this practice is discouraged, it will increase.

\section{Conclusions and recommendations}

Monarch rearing and tagging have become popular educational projects throughout the United States. We are not opposing local tagging and releasing of captured monarch butterflies or of reared butterflies that are first-generation offspring of locally captured wild adults. Concerns about the spread of Ophryocystis lead us to caution against using lab stocks as sources of adults for releases and to urge anyone rearing monarchs to become familiar with the symptoms of this disease (McLaughlin and Myers 1970).

There may be circumstances where the potential to enhance our knowledge or to gain other benefits

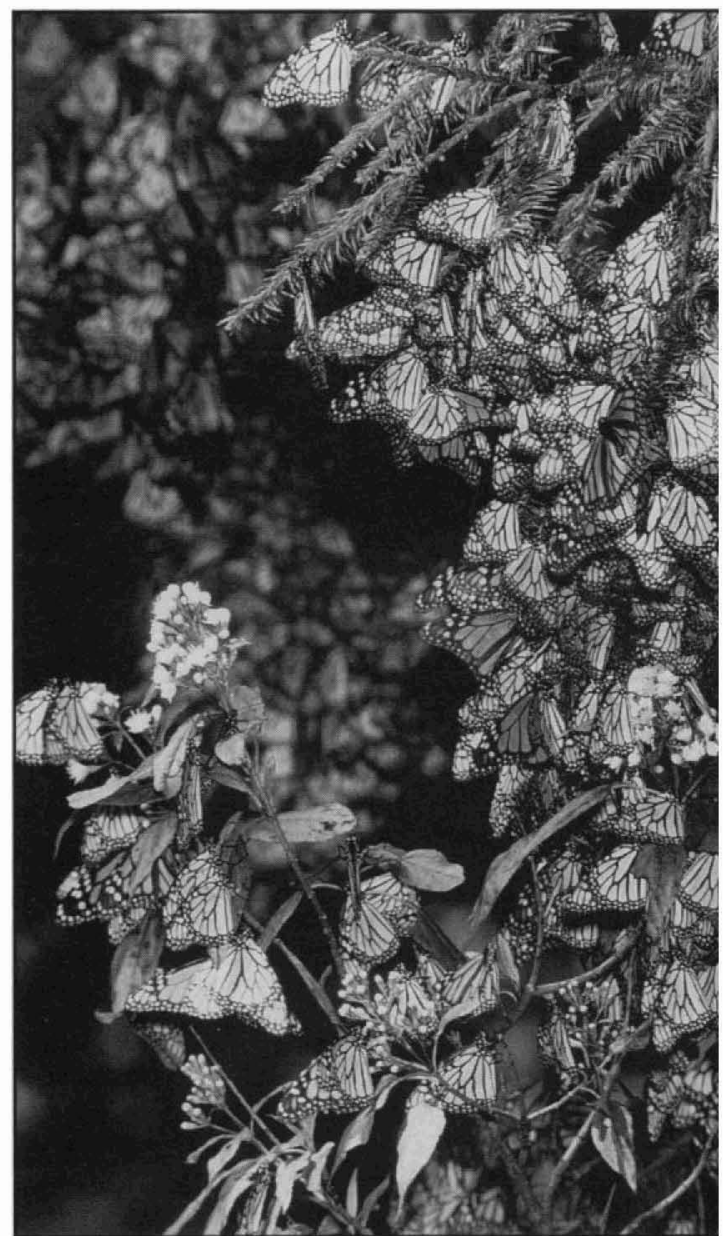

Overwintering monarch butterflies make dense clusters on fir trees (Abies religiosa) in Mexico. Photo: L. P. Brower.

outweighs the intrinsic risk of transferring organisms between populations. In the case of the monarch butterfly, however, we believe the costs-in terms of risks to monarch health and survival and confusion of future research-outweigh any of the currently posed benefits. Thus,

Table 1. Examples of the low frequencies of tagged monarch butterflies recaptured at least $100 \mathrm{~km}$ from their release sites.

\begin{tabular}{|c|c|c|c|c|}
\hline Monarch release sites & Release dates & Number released & Number recaptured & Recaptures per 1000 \\
\hline Presqu'ile Park, Ontario* & Fall 1992-1994 & 7400 & 12 & 1.6 \\
\hline Cape May, New Jersey ${ }^{\dagger}$ & Fall 1992-1994 & 1776 & 1 & 0.6 \\
\hline Southern Maryland ${ }^{\ddagger}$ & Fall 1989-1994 & 823 & 1 & 1.2 \\
\hline Eastern United States 5 & Fall 1992-1994 & 21,239 & 21 & 1.0 \\
\hline St. Marks National Wildlife Refuge, Florida" & Fall 1988-1992 & 8491 & 5 & 0.6 \\
\hline Overwintering sites, California & Winter 1986-1987 & 50,771 & 35 & 0.7 \\
\hline Oregon (transfers from Nebraska)* & Fall 1994 & 300 & 3 & 10.0 \\
\hline
\end{tabular}

'Donald A. Davis, 1995, unpublished data. Naturalist, Downsview, Ontario.

†Richard K. Walton, 1995, unpublished data. Cape May Bird Observatory, Cape May Point, NJ.

‡John F. Fales, 1995, unpublished data. Research scientist (retired), Huntingtown, MD.

SOrley Taylor, 1995, unpublished data. Department of Entomology, University of Kansas, Lawrence, KS.

"Tonya Van Hook, 1995, unpublished data. Department of Entomology, University of Florida, Gainseville, FL.

TNagano et al. 1993.

"Cherubini 1994. 
our collective position is that it is highly inadvisable to transfer anc. release living monarch butterflies in any life-history stages between populations that are naturally separated from each other. Transfers across the Rocky Mountains should definitely be discontinued.

Additionally, so that the information is available to future researchers, we request that those persons who have already made transfers publish documentation of the points of origin and release of the butterflies, the dates of collections (or rearings) and releases, and the numbers, stages, and sexes of all individual monarchs released. Possible places to publish these data include The Monarch Newsletter and the News of the Lepidopterists' Society. ${ }^{7}$

The problems we have described are not unique to monarch butterflies. Spread of disease, disruption of local adaptations, and the muddling of biogeographic and genetic patterns are risks to be considered before transferring any organisms between distant populations. While conservation biologists and many other scientists have become cautious about mixing populations, the monarch's situation reminds us that the general public and commercial ventures are also conducting transfers. The widespread marketing across the United States of wildflower seeds grown by a few nurseries is a potential case in point. Regulations and permit requirements prevent nonscientists from transporting most vertebrates, but many plants and invertebrates are not so regulated.

\section{References cited}

Anonymous. 1992. East meets West. The Monarch Newsletter 3(1): 2.

1994. Eastern monarchs travel over 700 miles through Oregon and northern California. The Monarch Newsletter 5(2): $1-2$.

Beetsma J. 1992. Preface. Experimental $\& \rightarrow T$ Applied Acarology 16: iv-vi.

Boecking O, Ritter W. 1994. Current status of behavioral tolerance of the honey bee Apis mellifera to the mite Varroa jacobsoni.

${ }^{6}$ Contact: The Monarch Program, P.O. Box 178671, San Diego, CA 92177.

${ }^{7}$ Contact: Marc and Maria Minno (Editors), 600NW 35th Terrace, Gainesville, FL 32607.
American Bee Journal 134: 689-694.

Brower AVZ, Boyce TM. 1991. Mitochondrial DNA variation in monarch butterflies. Evolution 45: 1281-1286.

Brower LP. 1985. New perspectives on the migration biology of the monarch butterfly, Danaus plexippus L. Pages $748-785$ in MA Rankin, ed. Migration: mechanisms and adaptive significance. Austin (TX): University of Texas.

. In press. Understanding and misunderstanding the migration of the monarch butterfly (Nymphalidae) in North America: 1857-1995. Journal of the Lepidopterists' Society.

Cherubini. 1994. New experiments in the east. The Monarch Newsletter 4(4): 2.

1995. Letter to the editor. The Monarch Newsletter 5(4): 6

Daugherty $\mathrm{CH}$, Cree A, Hay JM, Thompson MB. 1990. Neglected taxonomy and continuing extinctions of tuatara (Sphenodon). Nature 347: 177-179.

Eanes WF, Koehn RK. 1978. An analysis of genetic structure in the monarch butterfly, Danausplexippus L. Evolution 32: 784-797.

Herman WS, Brower LP, Calvert WH. 1989. Reproductive tract development in monarch butterflies overwintering in California and Mexico. Journal of the Lepidopterists' Society 43: 50-58.

Leong KLH, Kaya HK, Yoshimura MA, Frey DF. 1992. The occurrence and effect of a protozoan parasite, Ophryocystis elektroschirra (Neogregarinida: Ophryocystidae) on overwintering monarch butterflies, Danaus plexippus (Lepidoptera; Danaidae) from two California winter sites. Ecological Entomology 17: 338-342.

Malcolm SB, Zalucki MP, eds. 1993. Biology and conservation of the monarch butterfly. Los Angeles (CA): Natural History Museum of Los Angeles County.

McLaughlin RE, Myers J. 1970. Ophryocystis elektroscirrha sp. n., a neogregarine pathogen of the monarch butterfly Danaus plexippus (L.) and the Florida queen butterfly Danaus gilippus berenice Cramer. Journal of Protozoology 17: 300-305.

Nagano CD, Sakai WH, Malcolm SB, Cockrell BJ, Donahue JP, Brower LP. 1993. Spring migration of monarch butterflies in California. Pages 219-232 in SB Malcolm, MP Zalucki, eds. Biology and conservation of the monarch butterfly. Los Angeles (CA): Los Angeles County Museum of Natural History.

Sakai W. 1995. The season that was (not). The Monarch Newsletter 5(6): 7

Steffy G. 1994. Tagging thoughts. The Monarch Newsletter 5(3): 3.

Thorne ET, Williams ES. 1988. Disease and endangered species: the black-footed ferret as a recent example. Conservation Biology 2: 66-74.

Turelli M, Hoffmann AA. 1991. Rapid spread of an inherited incompatibility factor in California Drosophila. Nature 353: 440-442.

Tuskes PM, Brower LP. 1978. Overwintering ecology of the monarch butterfly, Danaus plexippus L., in California. Ecological Entomology 3: 141-153.

Urquhart FA. 1987. The monarch butterfly: international traveler. Chicago(IL): NelsonHall.
Urquhart FA, Urquhart NR. 1972. Insect migration studies. Pages 1-35 in Vol. 9: Annual newsletter to research associates. Toronto: University of Toronto.

1974. Insect migration studies. Pages 1-22 in Vol. 11: Annual newsletter to research associates. Toronto: University of Toronto.

Vane-Wright RI. 1993. The Columbus hypothesis: an explanation for the dramatic 19th century range expansion of the monarch butterfly. Pages 179-187 in SB Malcolm, MP Zalucki, eds. Biology and conservation of the monarch butterfly. Los Angeles (CA): Los Angeles County Museum of Natural History.

Wilson MH, Kepler CB, Snyder NFR, Derrickson SR, Dein FJ, Wiley JW, Wunderle JM, Lugo AE, Graham DL, Toone WD. 1994. Puerto Rican parrots and potential limitations of the metapopulation approach to species conservation. Conservation Biology 8: 114-123.

Lincoln P. Brower is a professor in the Department of Zoology, University of Florida, Gainesville, FL 32611. Linda S. Fink is a professor in the Department of Biology, Sweet Briar College, Sweet Briar, VA 24595. Andrew Van Zandt Brower is a National Science Foundation Postdoctoral Fellow in the Department of Entomology, American Museum of Natural History, Central Park West at 79th St., New York, NY 10024-5192. Kingston Leong is a professor in the Department of Biological Sciences, California Polytechnic University, San Luis Obispo, CA 93407. Karen Oberhauser is a research associate and Sonia Altizer is a graduate student in the Department of Ecology, Evolution, and Behavior, 100 Ecology Building, University of Minnesota, St. Paul, MN 55108. Orley Taylor is a professor and Danel Vickerman is a graduate student in the Department of Systematics and Ecology, University of Kansas, Lawrence, KA 66045. William H. Calvert is adjunct professor in the Department of Zoology, University of Florida, Gainesville, FL 32611. Tonya Van Hook is a graduate student in the Department of Entomology and Alfonso Alonso-Mejia is a graduate student in the Department of Zoology, University of Florida, Gainesville, FL 32611. Stephen B. Malcolm is a professor in the Department of Biological Sciences, Western Michigan University, Kalamazoo, MI 49008. Denis F. Owen is a professor in the School of Biological and Molecular Sciences, Oxford Brookes University, Oxford, England OX3 OBP. Myron $P$. Zalucki is a professor in the Department of Entomology, The University of Queensland, Brisbane, Australia Qld 4072. All of the authors are scientists or students who currently study, or have studied, the biology of the monarch butterfly. (C) 1995 American Institute of Biological Sciences. 